\title{
Back to the roots? Namíbia, Não!, de Aldri Anunciação
}

Henry Thorau ${ }^{1}$

Antônio é um cara bem legal, bem bonitão, tem uns 28 anos, veste um terno bem chique, gravata bem chique. "Ele está formado - acabou de terminar a Faculdade de Direito - e está superbem, porque conseguiu uma vaga no 'Curso Preparatório pro Concurso para Diplomata de Melanina Acentuada do Itamaraty'” (Anunciação, 2010, p. 20). Em seu primeiro dia de aula no curso, Antônio toma o café da manhã, apanha a pasta de estudos e prepara-se para sair. Nesse momento está de volta André, primo com o qual divide a casa, eterno estudante de direito que prefere gastar sua energia em farras noturnas. Ele diz: "Desista de sair da casa" (p. 21), mas Antônio não compreende e quando indaga sobre o motivo dessa advertência, André anuncia: "Saiu uma medida provisória!" (p. 22). Como Antônio continua sem entender, o primo esclarece:

Saiu uma Medida Provisória do Governo! [...] Cidadãos com traços e características que lembrem, mesmo que de longe, uma ascendência africana, a partir de hoje, 13 de maio de 2015, deverão ser capturados e deportados para os países africanos, como medida de correção do erro cometido pela então Colônia Portuguesa, e continuado pelo Império e pela República Brasileira. Erro esse que gerou quatro séculos de trabalhos gratuitos realizados por uma população injustamente transferida de suas terras de origem, para as terras brasilianas. Com o intuito de reparar esse gravíssimo erro cometido pela União, essa Medida prevê a volta desses cidadãos, e de seus descendentes, para terras africanas em caráter de urgência (Anunciação, 2010, p. 25).

No barzinho onde André costuma tomar chope, apareceram policiais com uma cópia da Medida Provisória na mão e lhe pediram que os acompanhasse até a delegacia. Lá ele foi informado por uma socióloga que o processo de retorno para a África obedecia às convenções humanas e democráticas, e ela lhe apresentou um catálogo com opções

\footnotetext{
${ }^{1}$ Doutor em cultura brasileira e portuguesa e professor na Universidade de Trier (Cátedra Carolina Michaelis de Vasconcelos), Trier, Alemanha. E-mail: thorau@uni-trier.de
} 
de países africanos para onde ele poderia ser enviado. Segundo a socióloga, ele, André, poderia escolher o país, ou melhor, o país africano de origem da família dele. Ao que André responde: "Desde quando sabemos onde estão nossos supostos familiares africanos?" (p. 24). Então ela resolveu sugerir um país: Namíbia. E André reage assustado: “Não! Não! Namíbia, Não! Esse país foi colonizado por alemães. Nada contra os alemães, mas eu não falo alemão!" (p. 26).

Esse suposto post-colonial encounter muito especial faz parte do texto da peça de teatro Namíbia, Não!, da autoria de Aldri Anunciação, o qual eu conheci em Berlim, quando ele esteve na cidade a fim de pesquisar material para sua monografia de bacharelado. Naquela ocasião, entrevistou-me para seu trabalho, intitulado Dramaturgia brasileira no teatro alemão. Jovem baiano, nascido em 1977, Anunciação é dramaturgo e ator, tendo atuado em cinema e também em produções de diretores de teatro muito bem conceituados no Brasil, como Gabriel Villela e Pedro Paulo Rangel. Sua formação universitária o habilitou como bacharel em Teorias Teatrais pela Universidade do Rio de Janeiro (Unirio), em 2006.

O seu texto Namíbia, Não!, de 2010, foi selecionado, nesse mesmo ano, para o II Ciclo Negro Olhar, evento patrocinado pela Funarte, no Rio de Janeiro. Ainda em 2010, a peça ganhou - junto com as de mais outros dois autores -, entre 67 textos teatrais, o Prêmio FAPEX ${ }^{2}$ de Teatro 2010 em Salvador. A estreia nacional da peça montada a partir do texto de Anunciação, no Teatro Castro Alves, em Salvador, na Bahia, no dia 17 de março de 2011, contou com a direção de Lázaro Ramos. $\mathrm{O}$ autor protagonizou o personagem Antônio, formado em direito e que conseguiu uma vaga no Curso Preparatório pro Concurso para Diplomata de Melanina Acentuada do Itamaraty.

Namíbia, Não! é sua primeira peça. Para mostrar e valorizar melhor o conteúdo, a estrutura, o conceito dramatúrgico do "texto teatral em um ato" (Anunciação, 2010, p. 15), é preciso voltar ao passado na história do teatro brasileiro. Historicamente, o colonial encounter pode ser lido, também no Brasil, como uma construção de fantasias de conquista e de domesticação europeias. No Romantismo - isto é, depois da fase de opressão e do quase total extermínio dos índios e ainda na época da escravatura -, as classes dominantes encenavam uma tentativa de harmonização, de conciliação, mais

\footnotetext{
${ }^{2}$ Fundação de Apoio à Pesquisa e Extensão Universitária.
} 
ainda, de uma fusão das etnias, entre europeus e "habitantes indígenas". O conceito-chave era o Indianismo.

Essas ideias também se refletiram na literatura da época. Como exemplo mais célebre é citado sempre o romance $O$ guarani, de José de Alencar - de 1857, ano da publicação de Madame Bovary, de Gustave Flaubert, na França -, no qual um fazendeiro acaba aceitando o amor da sua filha branca com um bon sauvage. Já a população negra servia como fundo pitoresco, colorindo os bastidores, nitidamente na pintura de gênero. ${ }^{3}$ E na literatura dramática, o negro só aparecia esporadicamente como semiprotagonista em comédias de costume, como o escravo Pedro em O demônio familiar, a quem o patrão diz:

Toma: é a tua carta de liberdade, ela será a tua punição de hoje em diante, porque as tuas faltas recairão unicamente sobre ti: porque a moral e a lei te pedirão uma conta severa de tuas ações. Livre, sentirás a necessidade do trabalho honesto e apreciarás os nobres sentimentos que hoje não compreendes (Alencar, 1965, p. 805).

O demônio familiar, também da autoria de José de Alencar, estreou em 1857, no mesmo ano em que foi publicado $O$ guarani. A peça fez muito sucesso, foi vista como "a primeira alta comédia original que aparece na cena brasileira" (Faria, 1987, p. 40). Ainda hoje, de vez em quando, a obra é encenada em palcos brasileiros. Augusto Boal, um dos diretores do Teatro de Arena e fundador do Teatro do Oprimido, não a valorizou muito nos anos 1960: "Ah sim, a peça esquece-se de debater a escravatura" (Boal, 1977, p. 47). Pergunto: mas, em Arena conta Zumbi o assim chamado primeiro musical brasileiro, de Augusto Boal e Gianfrancesco Guarnieri, com música de Edu Lobo, estreado em 1965, quer dizer, mais de cem anos depois - debate-se a escravatura? Vamos ver isso mais adiante.

Em papéis subalternos, e assim literalmente inofensivos, pessoas de "melanina acentuada" sempre encontraram e encontram até hoje, cinicamente, cenicamente e desumanamente, seu "lugar adequado" como "boa alma", "boa ama" (que expressões feias!). São vítimas bemvistas do riso de recalque de impulsos sexuais. Bem-amada e bem tolerada sempre foi a mulata como "la serva padrona"... Na cama e nos livros dos pais e filhos da casa grande (seja urbana ou campestre). Porém,

\footnotetext{
${ }^{3}$ A expressão pintura de gênero teve origem na pintura holandesa do século XVII e se refere às representações da vida cotidiana, do mundo do trabalho e dos espaços domésticos.
} 
causou escândalo o romance A mulata (1896), de Carlos Malheiro Dias, em que um homem branco, sexualmente dependente de uma mulata, termina se autodestruindo. Contudo, o romance navegava em plena onda do romance naturalista da virada do século; era a época do amor de perdição.

A "contrapartida homossexual" - sim, isso foi possível em 1895 representava o romance psicologizante curto. O bom crioulo, de Adolfo Caminha, tematizou o amour fou entre um marinheiro negro e um grumete branco: o negro é machão, ciumento que mete medo e, ao mesmo tempo, causa compaixão. $\mathrm{O}$ negro e a negra aparecem como ameaça e sedução do "continente escuro" - para parafrasear, ampliar e tomar literalmente o conceito de Sigmund Freud sobre a sexualidade feminina. Décadas mais tarde, a mulata virou o "milagre de peito e bunda", símbolo de sexo folclórico em guias turísticos a partir dos romances de Jorge Amado, como Gabriela, cravo e canela (1960). E o homem negro virou objeto de desejo na comunidade gay internacional, e mesmo nos textos poéticos etnológicos do escritor alemão Hubert Fichte. Todas essas são formas de exploração neocolonialista externas ou internas, abertas ou encobertas.

Os textos literários brasileiros, inclusive os do teatro e cinema, bem como as mídias em geral, sempre estiveram marcados pelo enlace entre diferença sexual e cultural. Sobretudo as mulheres negras lésbicas e homens negros gays foram e, infelizmente, ainda estão sendo enfocados como sintoma de patologia social, como tela de projeção negativa.

Um exemplo marcante dessa vertente é mostrado no filme Madame Satã (2002): um flashback que nos leva para a vida noturna dos anos 1930 no Rio de Janeiro. O protagonista é um ex-favelado, expulso da família pelos pais, que virou uma das mais famosas drag queens da época, transformando-se, a cada noite, em Josephine Baker. Com o objetivo de mostrar a ascensão e a queda, a vida autêntica de João Francisco de Santos (que nasceu em 1900 e morreu em 1976) nos anos totalitários do getulismo, o filme mostra a perpetuação dos clichês e estereótipos, o lado escuro do negro sensual, agressivo e violento, o negro e a negra como monsters of sex and crime. Imagens essas que, ainda hoje, os representantes do Movimento Negro se veem na dificuldade de desconstruir na memória coletiva.

A história demonstra os laços estreitos e contínuos entre race e gender na cultura e arte brasileiras, e mostra, também, como esses conceitos foram utilizados e muitas vezes até abusados na construção discursiva 
de identidade nacional. Nos debates do Modernismo nos anos 1920 - que se por um lado perpetuou a imagem do bon sauvage, por outro, a contracenou com a imagem do "comedor de gente" e da "criação do mundo" brasileiro autêntico por meio do canibalismo -, a população negra em princípio não apareceu no palco da história, nem foi mencionada. Só nos anos 1930 o Poder tentou fazer um ajuste populista do tema racial - no sentido mais amplo. Basta mencionar a meta da "democracia racial" - inventada por Gilberto Freyre -, nivelando as diferenças. As categorias do branqueamento, da mestiçagem e da morenidade - o ideal da integração do híbrido e do outro, sintetizado no sincretismo - criaram a imagem estilizada do homem cordial, que pouco correspondia à realidade empírica vivida.

Na luta contra o imperialismo estadunidense dos anos 1960 e 70, o teatro desempenhou, no processo de autoconscientização, um papel muito importante no Brasil (e também em outros países latinoamericanos, como, por exemplo, na Colômbia). No já mencionado musical brasileiro Arena conta Zumbi, de Augusto Boal e Gianfrancesco Guarnieri, estreado no dia 1o de maio de 1965 no Teatro de Arena em São Paulo, a luta dos negros da República dos Palmares em Alagoas contra os Senhores de Portugal foi adaptada ao século XX, transformada em resistência contra o imperialismo ianque. Em outras palavras, a causa dos negros foi utilizada como parábola, com a "linguagem escrava" 4 brechtiana e, em uma leitura marxista, "trans-funcionalizada" 5 em luta contra o capitalismo (global) da modernidade. Esse é um dos exemplos mais marcantes de abuso, ou digamos, de exploração ideológica, de exclusão - em nome da inclusão.

Se o sociólogo Abdias do Nascimento (1914-2011), um dos pais do Movimento Negro no Brasil, fundador do Teatro Experimental do Negro no Rio de Janeiro em 1944, tivesse publicado sua antologia Dramas para negros e prólogo para brancos não em 1961, mas em 1965, Arena conta Zumbi provavelmente não teria entrado. $\mathrm{O}$ Teatro Experimental do Negro, o primeiro teatro, como disse Abdias, "de negros e para negros", teve que fechar suas portas nos "anos de chumbo". Abdias exilou-se, mas a antologia ficou e continua sendo o primeiro

\footnotetext{
${ }^{4} \mathrm{O}$ termo original de Bertolt Brecht é "Sklavensprache" - no nosso contexto até parece um jogo de palavras de uma comicidade involuntária e cínica.

${ }^{5}$ Se assim se pode traduzir o termo original brechtiano "umfunktioniert".
} 
livro mais significativo sobre a temática até 2011, ano em que foram publicados os quatro volumes de Literatura e afrodescendência no Brasil, obra organizada por Eduardo de Assis Duarte (2011).

Revelar "a voz autêntica do negro, como raça e como homem de cor: a vida social", "restaurar, valorizar e exaltar a contribuição dos africanos à formação brasileira", eis as metas da antologia de Abdias do Nascimento (1961, p. 9 e p. 19). Nelson Rodrigues entrou nessa antologia dedicada ao Teatro Experimental do Negro com a sua tragédia Anjo negro, uma das primeiras peças redigidas por um autor branco na qual um negro desempenhou o papel principal. Escrita em 1946, a "tragédia em 3 atos" estreou em 2 de abril de $1948^{6}$ no Teatro Fênix, no Rio de Janeiro, com direção de Zbigniew Ziembinski. Anjo negro tratou abertamente da "luta de sexo" entre uma mulher branca e seu marido negro como "tema racial", assunto que, como escreveu Sábato Magaldi em 1965 na introdução de Teatro Completo II, de Nelson Rodrigues, "no Brasil existe quase sempre velado" (Magaldi, 1965, p. 23).

E os outros autores da antologia? Com exceção da farsa Auto da noiva (1946), de Rosário Fusco, o enredo de todas as oito obras restantes tem um fim trágico. Ou então são dramas históricos ou mitológicos ou histórico-mitológicos, como Além do Rio (1961), de Agostinho Olavo, uma transposição do mito da Medeia para o Brasil da época colonial. $\mathrm{Na}$ maioria, são dramas sociais da época, cuja ação se passa no interior ou na cidade (subúrbio e favela). Se não me engano, só duas peças evitam, literalmente falando, o "preto e o branco", o conflito entre os dois lados nitidamente opostos (Filhos de Santo, 1948, de José Morais Pinto, e Aruanda, 1946, de Joaquim Ribeiro). A maioria também evita mostrar a exploração brutal, "injustiças flagrantes" (Fernandes, 1972, p. 22), debatendo mais "injustiças disfarçadas" que não aparecem tão facilmente na superfície, mas que estão perturbando a mente e o comportamento social dos e das protagonistas e criam complexos de inferioridade e violações emocionais. Ninguém escapa dessa "obsessão tremenda de tudo quanto é branco" (Silveira, 1961, p. 390), constata o poeta negro João da Cruz e Sousa no texto O emparedado, de Tasso de Silveira, ainda em 1949. Na maioria das peças, as tentativas de arrebentar as grades da própria limitação, de transgredir o limite, são castigadas.

\footnotetext{
${ }^{6}$ Depois de dois anos de proibição pela censura.
} 
Na opinião de Florestan Fernandes, Nelson Rodrigues é o único autor que conseguiu uma superação das "barreiras de cor", mesmo que só simbolicamente, na mutação do comportamento, em uma escala de autoódio, via adaptação para a autoconfiança, e a conquista de autoestima do negro (Fernandes, 1972, p. 9). Como modelo serviu The emperor Jones, de Eugene O'Neill, de 1921, a primeira peça norte-americana com um protagonista negro forte, invertendo as condições de dependência. A "experiência" falhou no contexto dos acontecimentos políticos dos anos 1960 e 70, com o "preconceito de não ter preconceito" (Fernandes, 1972 , p. 23). Ainda na abertura política, o discurso oficial dificultou uma discussão não emocional, pragmática, do problema racial. Mesmo no movimento estudantil no Brasil, a causa negra, pelo que sei, durante muitos anos quase não existiu. Também depois da queda da ditadura, pouco mudou na violência estrutural ("strukturelle Gewalt", nas palavras de Johan Galtung), apesar de muitos esforços do Movimento Negro Unificado Contra a Discriminação Racial (MNU) e do Conselho de Participação e Desenvolvimento da Comunidade Negra, criado em 1984.

Só na década de 1980 e mais na de 90 apareceram novas formas de representação, tentativas de emancipação. Contudo, no início elas eram, na sua agressividade e no seu caráter "exclusivo" - e isso são processos psicológicos e sociais compreensíveis -, sobretudo reproduções das projeções discriminatórias da iconografia do "outro". Um dos primeiros dramaturgos negros que conseguiram superar esse esquema é Luiz Silva, nascido em 1951, mais conhecido sob seu nome de autor: Cuti. Os temas básicos de suas peças também são autoafirmação, respeito, autoestima, mas de uma forma mais sutil. Os personagens refletem mais, fazem uma introspeção psicológica como se fossem regressões para vidas antepassadas, descobrindo personalidades intrusas, digamos sombras jungianas, como no monodrama Dois nós na noite. As peças de Cuti fazem parte hoje do repertório do teatro negro do Brasil, e em 1991 também foram publicadas em livro, como Dois nós na noite e outras peças de teatro negro-brasileiro, em São Paulo. Trata-se de uma vertente avançada do teatro psicológico.

Voltemos dessas digressões para Namíbia, não!, uma obra avançada no sentido psicológico e sociológico, mas também dentro de uma onda de, digamos, repolitização do teatro.

Estamos novamente no apartamento de Antônio e André. De repente ouve-se o som de um helicóptero sobrevoando o bairro. Escutam-se 
gritos de uma senhora na rua. Antônio e André correm até a janela. A senhora acabou sendo capturada por policiais. Senhora (off): “Soltemme! [...] Eu não tenho a Melanina Acentuada... nem exaltada! [...] Eu sou parda, tá entendendo? Parda!" (Anunciação, 2010, p. 62-63). Ouvem-se os sons de um carro fechando portas, sons de carro dando partida e indo embora, cheio de pessoas capturadas (p. 67). Isso faz lembrar, para o leitor alemão, cenas da deportação dos judeus para os campos de concentração.

Dois nós na noite também podia ser o subtítulo ou o lema de Namíbia, não!. Antônio e André escondem-se, fecham-se no apartamento, trancam as portas para não serem capturados. De repente ouvem-se pedradas na janela, e um homem, um vizinho, lá fora gritando: "Saiam daí [...] por causa de vocês a rua inteira está sem luz. O governo diz que a luz só volta quando não morar nem mais um de Melanina Sublinhada na rua" (p. 69). É a voz da opinião pública? Onde estão os manifestantes que normalmente apoiam, de forma "politicamente correta", todos os oprimidos do mundo? Onde estão os defensores dos Direitos Humanos, da Human Rights Watch?

Antônio apenas comenta: “... a Comunidade Internacional? (irônico) A Comunidade Internacional... A triste onipresente impassividade..." (olha a plateia) (p. 97). Atônitos, André e Antônio assistem à televisão: estão sendo transmitidas reportagens sobre "a chegada do primeiro avião trazendo os cidadãos brasileiros de Melanina Acentuada capturados no Brasil" (p. 60). O repórter (voz em off) comenta: "Os nativos de Angola também estão presentes. Mas a recepção não é nada agradável. (Sons de multidão agressiva)... Eles protestam com faixas [...] parece que um cidadão angolano protesta com armas... e grita pela não entrada de brasileiros no país" (p. 61).

O que é real, o que é verossímil, o que é puro histerismo ou paranoia? Assistimos a uma alucinação? Antônio acalma André: "Você cochilou e teve um pesadelo, primo!" (p. 76). O que se passa com uma espantosa velocidade é uma mistura entre Huis clos (Sartre, 1944), teatro panfletário, parábola e teatro do absurdo à la Ionesco do século XXI, ${ }^{7}$ uma utopia negativa que dá arrepios - "o tempo em que se passa a ação da peça será sempre cinco anos à frente do tempo atual" (p. 19).

\footnotetext{
${ }^{7}$ Evocando Rhinocéros, de Ionesco: "sons em off de elefantes barrindo desesperados, como que em uma caçada” (Anunciação, 2010, p. 82). Ou: “Lá fora, a neve cai com mais intensidade” (p. 83).
} 
A eficiência e a crueldade de Namíbia, não! devem-se também ao fato de a obra se apresentar como uma comédia de boulevard, e não como uma obra de agit-prop, não como teatro explicitamente político, nem como drama social. Encontramo-nos além da literatura "marginal" no sentido mais amplo, além das conhecidas caraterísticas típicas de luta do teatro negro. Trata-se de um tema muito sério com os instrumentos do teatro de boulevard, da comédia de costumes, como se isso fosse a coisa mais natural do mundo, o que perturba o público. Nesse aspecto, Aldri Anunciação filia-se à vertente do diretor e dramaturgo George Tabori (1914-2007).

Os dois protagonistas Antônio e André não são outcasts, não são "dois perdidos numa noite suja" (Plínio Marcos), não são "capitães de areia" (Jorge Amado), não têm nenhum "manual prático do ódio" (Ferréz) debaixo do braço. Eles não precisam de rituais que ataquem a cultura burguesa, não têm uma mentalidade suburbana, mas urbana, não se gabam de um linguajar próprio, não representam o "código restringido", mas se articulam no "código elaborado". A ação não se passa na periferia, mas sim no centro social e cultural.

A peça evita, consequentemente, elementos folclóricos do morro, do afrossincretismo, do carnaval, mas também não entra no campo da sexual otherness, de certas construções de virilidade e de feminilidade. Ela não se define dentro do esquema da alteridade e da diferença cultural. Ao contrário. Os dois protagonistas funcionam perfeitamente na sociedade, eles representam a normalidade. A diferença se reduz unicamente à cor. A cor é o crime! Esse fato real-simbólico aumenta o medo dos antagonistas, que define a ameaça para o sistema estabelecido.

E é exatamente isso o que torna a peça tão inquietante. Aldri Anunciação articula uma problemática muito séria com diálogos eloquentes, jogos de palavras, com slapstick, com sarcasmo e ironia ferozes, até no cenário e no figurino. Como o próprio autor atuou na estreia, o texto cênico e o texto literário reforçaram mutuamente o conceito estilístico. Os elementos cômicos funcionam como estratégias subversivas. Dramaturgicamente falando, assim a "queda trágica" do herói, a catástrofe tem muito mais efeito. Aldri Anunciação realizou, com o riso do palhaço e, desse modo, com "humor negro", uma comédia negra nunca vista no Brasil.

No final, André “começa a maquiar o rosto com uma espécie de pancake branco" (p. 85), como se fosse uma alusão intertextual à conclusão do texto teatral Sortilégio (1951), de Abdias do Nascimento, 
que pressagia: "ninguém escapa da sua cor". Já o diretor e dramaturgo George Tabori escolheu como lema para a sua farsa Mein Kampf (Minha luta, 1987) versos de um poema do poeta alemão Friedrich Hölderlin: "Fazendo piadas sempre, sempre troçando? Vocês precisam! Oh, amigos! Isso me atinge na alma, pois só o desespero força a tanto!" (Hölderlin, 1946, p. 302, tradução nossa).

\section{Referências}

ALENCAR, José de (1965). O demônio familiar. In: Ficção completa e outros escritos. Vol. III. Rio de Janeiro: Aguilar.

ANUNCIAÇÃO, Aldri (2010). Namíbia, Não! Texto teatral em um ato. In: VERAS, Marcelo (org.). Prêmio Fapex de Teatro 2010. Salvador: Edufba.

DUARTE, Eduardo de Assis (org.) (2011). Literatura e afrodescendência no Brasil. 4 vols. Belo Horizonte: Editora UFMG.

BOAL, Augusto (1977). Técnicas latino-americanas de teatro. Rio de Janeiro: Hucitec.

CUTI (1991). Dois nós na noite e outras peças de teatro negro-brasileiro. São Paulo: Eboh.

FARIA, João Roberto (1987). José de Alencar e o teatro. São Paulo: Perspectiva, EDUSP.

FERNANDES, Florestan (1972). O negro no mundo dos brancos. São Paulo: Difel.

HÖLDERLIN, Friedrich (1946). Die Scherzhaften. In: Sämtliche Werke. Vol 1 [1798-1800]. Stuttgart: Cotta; W. Kohlhammer.

MADAME Satã (2002). Direção e produção de Karim Ainouz. Brasil: Lumiére. DVD (105 min.).

MAGALDI, Sábato (1965). Introdução. In: RODRIGUES, Nelson. Teatro quase completo. Vol. II. [S. 1.: s. n.]

NASCIMENTO, Abdias do (1961). Prólogo. In: NASCIMENTO, Abdias do (org.). Dramas para negros e prólogo para brancos. Rio de Janeiro: Edição do Teatro Experimental do Negro.

SARTRE, Jean-Paul (1944). Huis clos. Suivi de les mouches. Paris: Gallimard. 
SILVEIRA, Tasso de (1961). O emparedado. In: NASCIMENTO, Abdias do (org.). Dramas para negros e prólogo para brancos. Rio de Janeiro: Edição do Teatro Experimental do Negro.

Recebido em junho de 2013.

Aprovado em novembro de 2013.

\section{resumolabstract}

\section{Back to the roots? - Namíbia, Não!, de Aldri Anunciação}

Henry Thorau

Este artigo analisa como a "comédia negra" Namíbia, Não!, do jovem dramaturgo baiano Aldri Anunciação, elabora as últimas consequências da famosa democracia racial brasileira e dos direitos humanos, e como vai até os limites do discurso pós-colonialista "politicamente correto" no Brasil do século XXI.

Palavras-chave: teatro negro, teatro político, comédia, movimento negro, póscolonialismo, racismo, Aldri Anunciação.

\section{Back to the roots? - Namíbia, Não!, by Aldri Anunciação}

Henry Thorau

This article analyzes how the "black comedy" Namíbia, Não!, by the young playwright Aldri Annunciation, from Bahia, elaborates the last consequences of the famous Brazilian racial democracy and of the human rights, and how it goes until the limits of the "politically correct" post-colonialist discourse in Brazil of the XXI century.

Keywords: Black theatre, political theatre, comedy, Black movement, post colonial studies, race and gender, Aldri Anunciação. 